\title{
Turkish Adaptation of Behavioral Regulations in Sports Questionnaire and Reviewing Psychometry Properties: Validation and Reliability Study
}

\author{
Turan Çetinkaya $^{1} \&$ Ceren Mutluer ${ }^{2}$ \\ ${ }^{1}$ Ahi Evran University, Physical Education and Sports College, Turkey \\ ${ }^{2}$ Bolu Abant Izzet Baysal University, Department of Measurement and Evaluation in Education, Turkey \\ Correspondence: Ceren Mutluer, Bolu Abant Izzet Baysal University, Department of Measurement and Evaluation in \\ Education, Turkey
}

Received: September 23, 2018

Accepted: October 6, 2018

Online Published: October 18, 2018

doi:10.5430/ijhe.v7n5p185

URL: https://doi.org/10.5430/ijhe.v7n5p185

\begin{abstract}
Purpose of this study is to adapt Behavioral Regulation in Sports Questionnaire (BRSQ) which developed by Lonsdale, Hodge and Rose (2008) in Turkish and review psychometry properties. The scale consists of 24 items and 6 subdimension including intrinsic motivation, integrated regulation, identified regulation, introjected regulation, external regulation and motivation. Study group consists of total 681 student- athlete whom are licensed athletes and study at Physical Education and Sports College of Ahi Evran University, Erciyes University, Dumlupinar University and Çanakkale 18 Mart University. In order to determine psychometry properties of scale internal consistency, material and factor analysis and test- retest methods were applied. Cronbach alpha internal consistency coefficient of the measurement determined as follows; 0.790 for total points, 0.856 for intrinsic motivation subdimension, 0.838 for integrated regulation subdimension, 0.862 for identified regulation subdimension, 0.740 for introjected regulation subdimension, 0.788 for external regulation subdimension and 0.800 for motivation subdimension. In the analyzes performed, the data obtained from the exploratory and confirmatory factor analysis confirmed the 6-factor structure of the scale. In addition, scale-based analyzes yielded high test-retest scores. In this sense, it is considered that the scale is a valid and reliable measurement tool for the Turkish sample group.
\end{abstract}

Keywords: behavioral regulations in sports, participating motivation to sports, sports motivation, validity, reliability, questionnaire adaptation

\section{Introduction}

It is known that physical activity and sportive participation to following, independently of their type, both outdoor activities and free time activities or organized sports activities (activities by sports schools or physical education activities) by children, teenager and juveniles, has positive effect on their physical and psychological health (Koka \& Hein, 2003; Tzetzis et al; Duda et al.; Razakou et al 2003). May be most important reason for such physical and sportive activities to become and gain sustainability is individual motivation (Dirmen, 2014). To increase the number of participating individuals to sportive activities whose philosophy is do sports, factors that affect such participation must be disclosed (Edmunds, Ntoumanis \& Duda, 2008). Also, in order to actualize sportive participation, to provide consistency on participation and to create affective performance towards success, sportive motivation subject and its effect on participation must be disclosed (Engür, 2002).

Self Determination Theory, one of the theories to easily understand sportive motivation, discloses 2 main motivation types as intrinsic and extrinsic. When individual has intrinsic motivation, takes pleasure from the activity and feels satisfied; but when extrinsic motivation is involved, individual participates to activity due to various rewards or for outer factors (Deci \& Ryan, 2008; Gagne \& Deci 2005; Ingledew, Markland \& Sheppard, 2004). Self-regulation theory assumes there are different motivational regulations and highlights that every variable alters self-regulation level. Main principle of the self-regulation theory to provide both intrinsic and extrinsic motivation when applied to physical activity. Intrinsic motivation includes participating an activity due to natural pleasures provided and satisfactory behaviors. Many physical activities are delightful on their own and do not need any intrinsic or extrinsic rewards or promotions (Deci \& Ryan, 1985, 2000; Ryan \& Deci, 2000). On the contrary, extrinsic motivation characterizes activities done for a reward or some consequences such as avoiding a penalty or to get approval (Shokri, Viladrich, Cruz \& Alcaraz 2014).

Motivation concept has been one of the main subject in general psychology for long time and in sports and exercise literature, recently (Spray, John Wang, Biddle \& Chatzisarantis, 2006). According to Iso-Ahola (1989), motivation 
means efforts that initiates human behaviors, directs and sustains such behaviors. Motivation is intrinsic or extrinsic instincts which directs an individual to a specific behavior. Extrinsic stimulations are benefits and rewards to be gained when individual moves with extrinsic affects and fulfills necessary duty; intrinsic stimulations are attention comes from the individual's personality and pleasure taken from such (Wann, 1997). Motivation is a mechanism that pushes organism to behavior and determines the sustainability and frequency of such behaviors, various intrinsic and extrinsic factors that direct such behavior and provides functioning (Aydın, 2001).

Weinberg and Gould (1995) state that many reasons may affect sportive participation of individuals (weight balance, being vigorous). Writers highlight that personal reasons (family pressure, desire to participate an activity) and common motivation reasons (trait development, fun) may also be transcend in sportive participation motivation. Besides, researchers state that motivation concept may differ due to gender, age and cultural factors (Weinberg, Gould, 1995).

Behavioral responses may be related to competition level or caused by a situation requires ambition. Also, such response may be based on the individual's need of success or desire to be better (Martens, R. 1975; Weinberg, R., \& Gould, D. 2011).

Motivation may be accepted as source of athletic effort and participation. Understanding which reasons pushes an athlete to participate in a sport or an activity is stands as an important subject (Woodson, K. S, 2014). Sportive participation motivation may create opportunities towards improving sportive skill and traits, pleasure taken from sport activities (Frederick \& Ryan, 1993); Kilpatrick, Hervert \& Bartholomew, 2005), competitive structure (White, Duda \& Sullivan, 1991).

Behavioral regulation scale in sports, by (Lonsdale, Hodge, \& Rose, 2008), developed to determine sport participation motivation of participants in competitive sportive activities in view of self-determination theory. Such measure qualifies as a measure developed that assimilates measures which previously developed to scale many sportive participation motivation types (Pelletier at al 1995). Measure adapted to many different cultures previously. Spanish researchers (Viladrich, Torregrosa, \& Cruz, 2011) made Spanish version of measure and stated that psychometry properties have perfect adaptation. Besides, Holland, Sharp, Woodcock, Cumming, \& Duda (2010) reviewed the psychometry properties of measure and provided to be valid and credible. Writers, validated 6-factor structure of the measure as Intrinsic Regulation, Integrated Regulation, Defined (Identity) Regulation, Introjected Regulation, Extrinsic Regulation and Amotivational on juvenile and adult sample groups. Iranian researchers Ahmadi, N., Abdoli, B., Rezvani, M. (2017) conducted validation and credibility studies of the measure on Iranian sample group.

Some adaptation studies are also made in our country on different perspectives under sportive participation motivation and sportive motivation headlines. Kazak (2004) has studied psychometry properties of sportive motivation measure with the adaptation study. Nevertheless, Ersöz, Aş̧̧ı and Altıparmak (2012) conducted validation and credibility study of the Behavioral Regulations Scale in Sports-2. Researchers state that Turkish version of the measure is valid and credible to scale motivational orientation in exercise of students in $17-30$ age spans.

This study, conducted to determine motivational factors towards participation and disclosing sportive participation reasons, considered to be important in aspect of gaining consisted behaviors in the name of sport participation. Additionally, motivation subject which has become a popular concept in sports psychology recently, considered to have importance to be handled regarding sportive participation. From this point, purpose of this study is to adapt Behavioral Regulation Scale in Sports (BRMS) in Turkish and review psychometry properties.

\section{Method}

\subsection{Study Group}

Study group consists of total 681 student- athlete whom are licensed athletes and study at Physical Education and Sports College of Ahi Evran University, Erciyes University, Dumlupınar University and Canakkale 18 Mart University. $395(58 \%)$ of the participants are male, $286(42 \%)$ are female. Participating student- athlete age groups are as follows; $349(51,2 \%)$ of the participants are in age group 18-21, $303(44,5 \%)$ of the participants are in age group 22- 25, $22(3,2 \%)$ of the participants are in age group 26- 29 and $7(1 \%)$ of the participants are in age group 30 and above.

\subsection{Data Collection Tools}

Personal information form and Behavioral Regulations in Sports Questionaire were applied to study group.

\subsection{Behavioral Regulations Scale in Sports}

Required permissions to adapt Behavioral Regulations in Sports Questionaire, developed by Lonsdale, Hodge \& 
Rose, (2008), were granted by contacting Chris Lonsdale. Also, necessary infrastructural studies were conducted, such as collecting adaptation versions of the scale on different cultures from responsible scale owner, to adapt Turkish and to review psychometry properties. Measure is 7-likert type measure consists of 24 items and 6 subdimensions. Participants mark their participation levels regarding every statement in scale on 7-likert type grading measure vary between not true (1) and very true (7). Sub-dimensions are as follows; intrinsic motivation (e.g. because I enjoy doing sports), integrated regulation (e.g. Because it is part of who I am), idefined regulation (e.g. Because benefits from sport is important for me), introjected regulation (e.g. Because if I quit sports I would be embarrassed), external regulation (e.g. Because if I do not do sports people around me would not be pleased with me) and amotivation (e.g. But I do not know why I do sports). Cronbach alpha internal consistency coefficient of the measurement determined as follows; 0.790 for total points, 0.856 for intrinsic motivation sub-dimension, 0.838 for integrated regulation sub-dimension, 0.862 for identified regulation sub-dimension, 0.740 for introjected regulation sub-dimension, 0.788 for external regulation sub-dimension and 0.800 for amotivation sub-dimension.

\subsection{Data Collection}

Translation- Back-Translation technique applied on Turkish translation of Behavioral Regulation in Sports Questionaire (BRSQ). Scale, primarily, translated into Turkish by four researchers from English Language Teaching and Physical Education and Sports. Translations were compared, and common articles determined. Turkish version of the measure was translated into English again by two different experts on English Language Teaching. Finally, original version of the scale and the re-translated version were compared and the best representing articles were collected. Revised scale was applied to student- athlete on 2017- 2018 educational year.

\subsection{Data Analysis}

On the first step of the analysis process, missing value review was made. 21 participants did not answer more than $(10 \%)$ of the articles in the measure on the data matrix and information related to such participants were excluded from data set. 7 participants observed to give the same points to every article on the scale, their opinions were also excluded from evaluation. Following this, missing value rate reviewed on data matrix item distribution and missing value rate observed to be below (5\%) and regression assignment method used to assign missing values. Also, extreme value and normality distributions reviewed to minimize statistical mistake rate. SPSS 20 program was used for descriptive analysis and exploratory factor analysis of data, Lisrel 8.7 program was used for confirmatory factor analysis of data. Data reviewed for suitability to principal component analysis with Kaiser- Meyer- Olkin (KMO) and barlett tests before factor analysis (Fayers, Hays \& Hays; 2005). Kaiser- Meyer- Olkin (KMO) sample sufficiency analysis results show KMO value as 0.879 and barlett test result as $\left[\mathrm{x}^{2}=7602,690, \mathrm{df}=276, \mathrm{p}<.000\right]$.

\subsection{Construct Validity}

\subsubsection{Exploratory Factor Analysis}

Factor analysis used to provide construct validity of measure means used in study. Purpose of the factor analysis given below (Tabachnick and Fidell, 2006; Thompson, 2004):

- Collect many observed variables under less dimension,

- Making definition by using observed variables,

- Determination of sub-dimensions of developed scale, determination of which item belongs to which sub-dimension

- Determination of suitability of scale dimensions for different culture and groups in adaptation studies.

Factor analysis separate in two as Exploratory Factor Analysis (EFA) and Confirmatory Factor Analysis (CFA). Main purpose of the EFA is reduce number of observed variables to determine sub dimensions of the scale. In this study, primarily EFA applied to determine sub-dimensions and items that represent these sub-dimensions. EFA results regarding Behavioral Regulation in Sports Questionaire given in Table 1.

In order to provide construct validity in this study, as first phase, data regarding Behavioral Regulations Scale in Sport reviewed with exploratory factor analysis by using SPSS 20.00 program. While conducting EFA limited to six-dimension construction of the developed measure. For an article to become a good representative/ indicative in sub-dimensions, factor load must be 0,30 and above (Büyüköztürk, 2003). As result of EFA, 0,30 and above were processed. Once, analysis results evaluated factor construction collected for scale by Lonsdale et al (2008) were confirmed. Determined as 6-factor after Principal Component Factor Analysis exchange (varimax) process. Besides, obtained factor construct explains $66,18 \%$ of the measure. Factor load values of the scale items were between 0.397 and 0.790 . 
Table 1. Factor Load Values of Items and Explained Variance

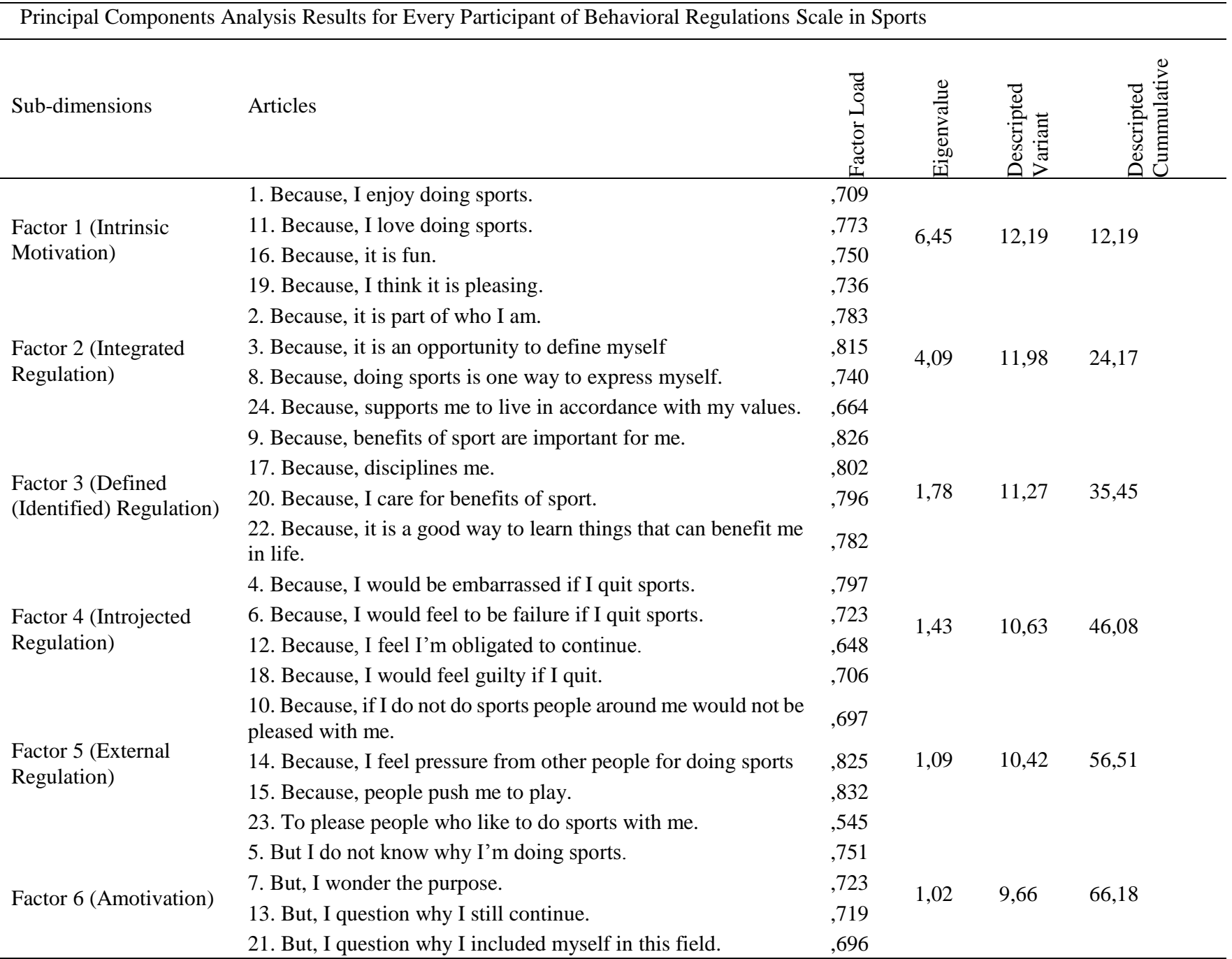

\subsubsection{Confirmatory Factor Analysis}

CFA analysis made to disclose confirmatory construct validity of scale. CFA is a process to create implicit variables based on observed variables through a previously developed model (Schumarker and Lomax, 1996).

Table 2. Break points for structural equation modeling indices (Çokluk, Şekercioğlu and Büyüköztürk, 2014).

\begin{tabular}{lll}
\hline Fit Indices & Criteria & Break Points \\
\hline$\chi^{2}$ & $\mathrm{p}>0,05$ & \\
\hline$\chi^{2} / \mathrm{sd}$ & & $\leq 2=$ Perfect Fit \\
& & $\leq 2,5=$ Perfect Fit (in small samples) \\
& $\leq 3=$ Perfect Fit (in large samples) \\
& $\leq 5=$ medium fit level \\
\hline GFI & $\geq 0,90=$ Perfect fit \\
AGFI & \\
CFI & \\
NNFI(TLI) & $\leq 0,080=$ Acceptable Fit \\
\hline RMSEA & $\leq 0,050=$ Perfect Fit \\
\hline
\end{tabular}


In this research, 24 articles representing the six dimensions were used for CFA. LISREL 8.80 program used for CFA analysis. Since 'Relative Multivariate Kurtosis' value excesses 1 during CFA analysis, conducting CFA analysis seemed more appropriate in accordance with Robust ML method. Obtained diagram given in Figure 1.

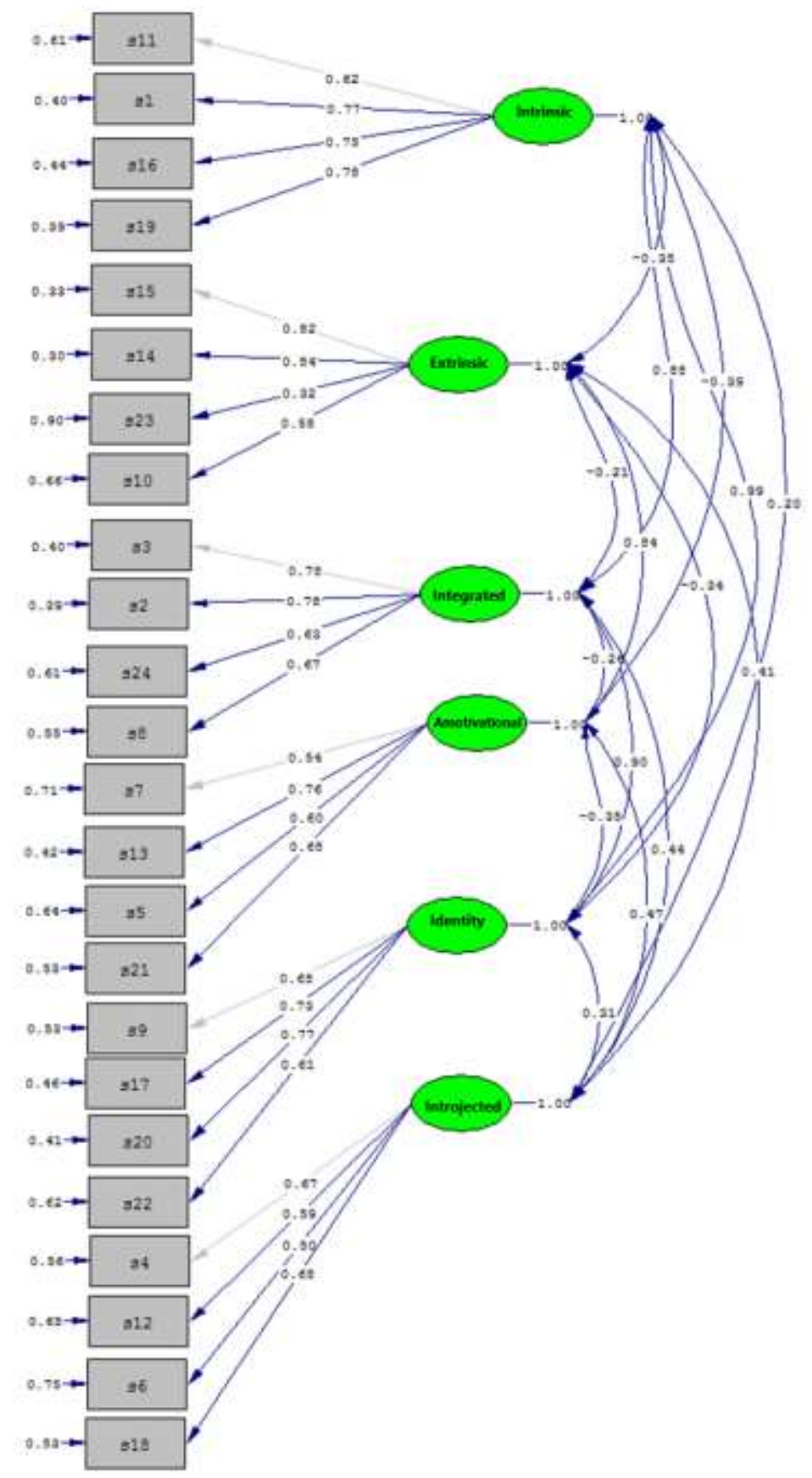

Figure 1. CFA analysis of Behavioral Regulation in Sports Questionaire (Standardized Solution) 
Figure 1. Belongs to CFA analysis of the Behavioral Regulation in Sports Questionaire. When every item processed, every item observed to value over 0,30 factor load value. Similarly, when error variance value reviewed for every article observed to be below 0,90. These two parameters prove that they are good representatives for scale dimensions.

Table 3. Model Data Fit Value Regarding Behavioral Regulation in Sports Questionaire (Standardized Solution)

\begin{tabular}{|c|c|c|c|c|c|c|c|c|c|}
\hline & $\chi^{2} \quad(\mathrm{sd})$ & RMSEA & GFI & AGFI & CFI & NNFI & $\lambda$ & $\varepsilon$ & $\begin{array}{l}\text { Correal } \\
\text { ation } \\
\text { between } \\
\text { factors }\end{array}$ \\
\hline $\begin{array}{l}\text { 1.Grade 6- } \\
\text { Factor } \\
\text { Robust } \\
\text { ML }\end{array}$ & $\begin{array}{l}753,78 \\
(237)\end{array}$ & 0,057 & 0,89 & 0,86 & 0,97 & 0,97 & $0,32-0,84$ & $\begin{array}{l}0,39-0,9 \\
0\end{array}$ & None \\
\hline
\end{tabular}

Above given table contains CFA analysis results of first grade 6-factor Robust ML estimation value of Behavioral Regulation in Sports Questionaire. Model Data fit indices for fit between established model and estimated model is provided in above table. Chi-square statistics reviewed for first model data fit indices. Chi-square value calculated as considerable large. Since chi-square is a fit indice effected by sample size; when divided to degree of freedom, even though resulted very close to the critical value 3 , resulted greater than $3 \cdot \chi^{2} /$ sd statement being greater than $3\left(\chi^{2}\right.$ $/ \mathrm{sd}=753,78 / 237=3,18$ ) shows that there is significant difference between established model and existing model. When chi-square indice observed it can be seen that model data fit is not provided.

RMSEA value presents robust statistic between model data fit indices. When acceptable RMSEA value (RMSEA $=0,057$ ) compared with criteria defined in table 2.2 it is on acceptable level. This finding shows established model for sample in this study provides model data fit.

When GFI, AGFI, CFI and NNFI values compared with Table 2, GFI and AGFI values observed to be close to set point but slightly lower. Model data fit considered to be provided for CFI and NNFI values.

To become an indicator implicit variable, factor load must be 0,30 minimum and error variance must be 0,90 maximum (Çokluk, Şekercioğlu\& Büyüköztürk 2010). Such rule applies for factor load values on standardized solutions. When factor load values reviewed, observed to value between 0,32 and 0,84 . This condition proves every item is good representative of dimensions.

When error variances reviewed, these values differ between 0,39 and 0,90 . Error variance for 0,90 and above indicates that article must be excluded from analysis. Just as comment made regarding factor loads, since there is no item with error variance 0,90 and above; articles in measure are good indicators of specific dimensions.

No correlation between dimensions enabled first grade CFA to be made for CFA. Integrated approach should be selected to interpret model data fit and give right decision. Therefore, every model data fit indice were also reviewed. As result of review, general opinion is model data fit is achieved. Thus, provides construct validity with CFA.

Table 4. Cronbach Alpha Coefficients for Behavioral Regulation in Sports Questionaire and Sub-dimensions of Such

\begin{tabular}{|c|c|c|}
\hline Reliability Statistics & Cronbach's Alpha & $\mathrm{N}$ of Items \\
\hline $\begin{array}{l}\text { Behavioral Regulations Scale in } \\
\text { Sports Total }\end{array}$ & .790 & 24 \\
\hline Intrinsic Motivation & .856 & 4 \\
\hline Integrated Regulation & 0,838 & 4 \\
\hline Identitied Regulation & 0,862 & 4 \\
\hline Introjected Regulation & 0,740 & 4 \\
\hline External Regulation & 0,788 & 4 \\
\hline Amotivation & 0,800 & 4 \\
\hline
\end{tabular}

Reliability co-efficient calculated to determine Behavioral Regulation in Sports Questionaire with minimum error. For reliability calculation, Cronbach Alpha values for every dimension and total of measure were reviewed. Reviewed alpha co-efficient observed to be above $0,70\left(\alpha_{\text {Intrinsic Motivation }}=0,856 ; \alpha_{\text {External Regulation }}=0,788 ; \alpha_{\text {Integrated }}\right.$ 
Regulation $=0,838 ; \alpha_{\text {Identity Regulation }}=0,862 ; \alpha_{\text {Amotivation }}=0,800 ; \alpha_{\text {Introjected Regulation }}=0,740 ; \alpha_{\text {Total Scale }}=0,790$ ). Therefore, statement of measure mean measure with minimum error and has high credibility can be made. Credibility of measure is also reviewed with test- re-test method and applied to survey research group with 3-week interval to determine stabilization of measure. Once controlled for missing value, correlation between two applications reviewed. Stability co-efficient found with test- re-test method as follows; $\left(\mathrm{r}_{\text {Total Scale }}=0,926\right)$ for total measure, $\left(\mathrm{r}_{\text {Intrinsic Motivation }}=0,868\right)$ for intrinsic regulation sub-dimension, $\left(\mathrm{r}_{\text {Integrated Regulation }}=0,915\right)$ for integrated regulation sub-dimension, $\left(r_{\text {Identitied Regulation }}=0,892\right)$ for defined (identity) regulation sub-dimension, $\left(r_{\text {External Regulation }}=0,903\right)$ for extrinsic regulation sub-dimension, $\left(\mathrm{r}_{\text {Amotivation }}=0,878\right)$ for amotivation sub-dimension, $\left(\mathrm{r}_{\text {Introjected Regulation }}=0,912\right)$ for introjected regulation sub-dimension. In accordance with these findings, measured construction can be interpreted as stable and contain minimum errors.

\section{Discussion and Result}

Until today, many measures developed regarding sport participation motivation and sport motivation and used with adaptations on different cultures. With this study, Turkish adaptation of Behavioral Regulation in Sports Questionnaire which developed by Lonsdale, Hodge, Rose., (2008) and already adapted to different cultures, was aimed. This study started with the idea of assisting studies regarding determination of sportive participation and sustainability of such.

Primarily, with translation- back translation technique preparatory study made towards measure means applicability for Turkish culture. Measure articles separately translated by academics from sports science and philology and also by researchers who study on adaptation; then language equivalency grades evaluated and agreed articles applied on students and included to measure.

Distribution of article-factor components reviewed with explanatory factor analysis in order to disclose construct validity of Behavioral Regulation in Sports Questionnaire (Tabachnick \& Fidell, 2007). With conducted analysis, measure fit mostly with original version and measure articles show harmonic distribution under defined factors. On the next step of the analysis, different from the one applied with original version of the measure, subject of grade of fit for Turkish culture is reviewed. Obtained findings result theoretically and statistically highly fit of theoretic estimated model with Turkish adaptation of measure.

As conclusion, Behavioral Regulation in Sports Questionnaire is considered to be valid and credible measurement mean to scale Turkish university students' sportive participation motivation.

\section{References}

Ahmadi, N., Abdoli, B., Rezvani, M. (2017). Psychometric Properties of Persian Version of the Behavioral Regulation in Sport Questionnaire (BRSQ). Sport Psychology Studies, 6(22), 31-46.

Aydın A. (2001). Gelişim ve Öğrenme Psikolojisi, Alfa Yayınları, İstanbul, s. 144.

Çokluk, Ö., Şekercioğlu, G., \& Büyüköztürk, Ş. (2010). Multivariate statistics for the social sciences: SPSS and LISREL applications. Ankara: Pegem Akademi.

Deci, E.L., \& Ryan, R.M. (1985). Intrinsic motivation and self-determination in human behavior. New York, NY: Plenum. https://doi.org/10.1007/978-1-4899-2271-7

Deci, E.L., \& Ryan, R.M. (2000). The «what» and «why» of goal pursuits: Human needs and the self-determination of behavior. Psychological Inquiry, 11, 227-268. https://doi.org/10.1207/S15327965PLI1104_01

Deci, E.L., \& Ryan, R.M. (2008). Self-determination theory: A macrotheory of human motivation, development, and health. Canadian Psychology/Psychologie Canadienne, 49(3), 182. https://doi.org/10.1037/a0012801

Dirmen, A. (2014). Farklı liglerde oynayan kadın futbol takımı oyuncularının başarı motivasyon düzeylerinin karşıllaştırılması (Yayımlanmamış yüksek lisans tezi). Marmara Üniversitesi, Sağlık Bilimleri Enstitüsü, İstanbul.

Duda, J. L., Quested, E., Haug, E., Samdal, O., Wold, B., Balaguer, I., Cruz, J. (2013). Promoting Adolescent health through an intervention aimed at improving the quality of their participation in Physical Activity (PAPA): Background to the project and main trial protocol. International Journal of Sport and Exercise Psychology, 11(4), 319-327. https://doi.org/10.1080/1612197X.2013.839413

Edmunds, J., Ntoumanis, N. \& Duda, J. L. (2008). Testing a self-determination theory-based teaching style intervention in the exercise domain. European Journal of Social Psychology, 38(2), 375-388. https://doi.org/10.1002/ejsp.463 
Engür, M. (2002). Elit sporcularda başarı motivasyonun, durumluk kaygı düzeyleri üzerine etkisi (Yayımlanmamış doktora tezi). Ege Üniversitesi, Sağlık Bilimleri Enstitüsü, İzmir.

Ersöz, G., Aşçı, F.H. \& Altıparmak, E. (2012). Egzersizde Davranışsal Düzenlemeler Ölçeği-2: Geçerlilik ve güvenilirlik çalışması. Türkiye Klinikleri Journal of Sports Sciences, 4(1), 22-31.

Fayers, P. M., Hays, R., \& Hays, R. D. (Eds.). (2005). Assessing quality of life in clinical trials: methods and practice. Oxford University Press, USA.

Frederick, C., \& Ryan, R. (1993). Differences in motivation for sport and exercise and their relations with participation and mental health. Journal of Sport Behavior, 16(3), 124-146.

Gagne, M., \& Deci, E.L. (2005). Self-determination theory and work motivation. Journal of Organizational Behavior, 26(4), 331-362. https://doi.org/10.1002/job.322

Holland, M.J., Sharp, L.A., Woodcock, C., Cumming, J., \& Duda, J.L. (2010). Validity and reliability of the Behavioral Regulation in Sport Questionnaire (BRSQ) with youth athletes. Journal of Sport and Exercise Psychology, 32 Suppl., 175-176.

Ingledew, D.K., Markland, D., \& Sheppard, K.E. (2004). Personality and self-determination of exercise behaviour. Personality and Individual Differences, 36(8), 1921-1932. https://doi.org/10.1016/j.paid.2003.08.021

Iso-Ahola, S. E. (1989). Motivational foundations of leisure. Em E. L. Jackson \& T. L. Burton (Eds.), Understanding Leisure and Recreation: Mapping the Past, Charting the Future (pp. 35-51). State College, PA: Venture Publishing.

Kazak, Z. (2004). "Sporda Güdülenme Ölçegi -SGÖ-"nin Türk sporcuları için güvenirlik ve geçerlik çalısması. Hacettepe Üniversitesi Spor Bilimleri Dergisi, 15(4), 191-206.

Kilpatrick, M., Hebert, E., \& Bartholomew, J. (2005). College students' motivation for physical activity: Differentiating men's and women's motives for sport participation and exercise. Journal of American College Health, 54(2), 87-94. https://doi.org/10.3200/JACH.54.2.87-94

Koka, A., \& Hein, V. (2003). Perceptions of teacher's feedback and learning environment as predictors of intrinsic motivation in physical education. Psychology of Sport and Exercise, 4(4), 333-346. https://doi.org/10.1016/S1469-0292(02)00012-2

Martens, R. (1975). Social psychology and physical activity. Ann Arbor, MI: Harper \& Row.

Pelletier, L.G., Tuson, D.M., Fortier, M.S., Vallerand, R.J., Brière, N.M., \& Blais, M.R. (1995). Toward a new measure of intrinsic motivation, extrinsic motivation and amotivation in sports: The Sport Motivation Scale. Journal of Sport and Exercise Psychology, 17, 35-53. https://doi.org/10.1123/jsep.17.1.35

Razakou, F., Tsapakidou, A., Beis, C., \& Tsompanaki, T. (2003). Investigating Concrete Factors Related to the 7-12 Year Old Children's Occupation with out of School Athleticism. Inquiries in Sport \& Physical Education, 1(2), $143-151$.

Ryan, R.M., \& Deci, E.L. (2000). Self-determination theory and the facilitation of intrinsic motivation, social development and wellbeing. American Psychologist, 55, 68-78. https://doi.org/10.1037/0003-066X.55.1.68

Schumacker, R. EL, \& Lomax, R. G. (1996). A beginner's guide to structural equation modeling. Mahwah, NJ; Lawrence Erlbaum.

Shokri, A., Viladrich, C., Cruz, J., \& Alcaraz, S. (2014). Adapting BRSQ to assess coach's perception of athletes' motivation: Internal structure analysis. Procedia - Social and Behavioral Sciences, 159, 497-505. https://doi.org/10.1016/j.sbspro.2014.12.413

Spray, C., John Wang, C. K., Biddle, S., \& Chatzisarantis, N. (2006). Understanding motivation in sport: An experimental test of achievement goal and self determination theories. European Journal of Sport Science, 6(1), 43-51. https://doi.org/10.1080/17461390500422879

Tabachnick, B. G., \& Fidell, L. S. (2007). Using multivariate statistics. Allyn \& Bacon/Pearson Education.

Thompson, B. (2004). Exploratory and confirmatory factor analysis: Understanding concepts and applications. Washington, DC: American Psychological Association. https://doi.org/10.1037/10694-000 
Tzetzis, G., Kakamoukas, V., Goudas, M., \& Tsorbatzoudis, C. A. (2005). Comparison of Physical Activity Patterns and Physical Self-Perception in Obese and non-Obese Children. Inquiries in Sport \& Physical Education, 3(1), 29-39.

Viladrich, C., Torregrosa, M., \& Cruz, J. (2011). Calidad psicométrica de la adaptación española del Cuestionario de Regulación Conductual en el Deporte. Psicothema, 23, 786-794.

Wann DL. (1997). Sport psychology. Upper Saddle River, New Jersey: Pretice-Hall. 158- 183.

Weinberg R, Gould D. (1995). Foundations of Sport and Exercise Psycology. Human Kinetics. 60- 72.

Weinberg, R., \& Gould, D. (2011). Foundations of sport and exercise psychology. (4th ed.). Champaign, IL: Human Kinetics.

White, S., Duda, J., \& Sullivan, C. (1991). The relationships of gender, level of sport involvement, and participation motivation to goal orientation. American Alliance for Health Physical Education, Recreation and Dance, 95.

Woodson, Kimberly S.. (January 2014). Motivation, achievement orientation, and competition in collegiate track and field athletes (Master's Thesis, East Carolina University). Retrieved from the Scholarship. 